\title{
Condição Infantil e Autoridade Amorosa em Johann Friedrich Herbart
}

\author{
Cláudio Almir Dalbosco' \\ 'Universidade de Passo Fundo (UPF), Passo Fundo/RS - Brasil
}

RESUMO - Condição Infantil e Autoridade Amorosa em Johann Friedrich Herbart $^{1}$. O presente ensaio investiga o modo como Johann Friedrich Herbart trata do problema do autogoverno pedagógico no âmbito da educação infantil, tomando como referência o primeiro livro, intitulado Governo das Crianças (Regierung der Kinder) de sua obra Pedagogia Geral (Allgemeine Pädagogik), publicada em 1806. Dividindo-se em três partes, investiga, na primeira, a concepção herbartiana de criança, tratando, na segunda parte, do perfil do educador. Conclui, por fim, na terceira parte, com algumas críticas à pedagogia infantil herbartiana. Retém, como resultado importante da investigação, que a postura ativa do sujeito educacional só pode ser alcançada, no âmbito da educação infantil, quando estiver ancorada na pedagogia da autoridade amorosa.

Palavras chave: Pedagogia. Autoridade. Amor. Governo. Autogoverno.

ABSTRACT - Children's Condition and Loving Authority in Johann Friedrich Herbart. This essay investigates how Johann Friedrich Herbart addresses the problem of pedagogical self-government in early childhood education, taking as reference the first book entitled Government of children (Regierung der Kinder) of his work General Pedagogy (Allgemeine Pädagogik), published in 1806. Divided into three parts, the essay examines the Herbartian conception of the child in the first one, and addresses the profile of the educator in the second. Finally, in the third part, it brings some critiques of Herbartian children's pedagogy. An important result of the research is: the active attitude of the educational subject can only be achieved, in the context of early childhood education, when it is grounded in the pedagogy of loving authority.

Keywords: Pedagogy. Authority. Love. Government. Self-Government.

Educação \& Realidade, Porto Alegre, v. 43, n. 3, p. 1131-1148, jul./set. 2018.

1131 http://dx.doi.org/10.1590/2175-623674872 
Condição Infantil e Autoridade Amorosa em Johann Friedrich Herbart

\section{Introdução}

A Pedagogia Geral (Allgemeine Pädagogik), publicada em 1806, pelo pedagogo alemão Johann Friedrich Herbart (1776-1841), é uma das principais obras pedagógicas do século XIX. A obra divide-se em três livros: o primeiro intitula-se A Finalidade da Educação: sentido geral; o segundo livro, A Multiplicidade do Interesse e; por fim, o terceiro denomina-se Fortaleza do Caráter Moral. Não é nada fácil compreender esta arquitetônica e nem o possível fio condutor que a articula. Dietrich Benner, em seu estudo A Pedagogia de Herbart (Die Pädagogik Herbarts), oferece importante contribuição aos estudos herbartianos. Segundo ele, a arquitetônica da referida obra é constituida pela tipologia tripartite da ação pedagógica, governo, ensino e disciplina (Benner, 1993).

Deste modo, segundo a interpretação de Benner, o conceito de ação pedagógica é central à teoria educacional de Herbart, permitindo-lhe pensar a relação entre educador e educando, adulto e criança, professor e aluno de maneira original. Tal fato projeta o pedagogo alemão muito à frente das teorias educacionais de sua época. A Pedagogia ocidental se ocupou, desde suas origens, do problema da relação entre educador e educando, concebendo a educação como principal força de aperfeiçoamento permanente do ser humano. A Paideia grega, a Instructio latina e a Bildung alemã foram grandes projetos plurais, elaborados a muitas mãos, que problematizaram a vulnerabilidade da condição humana e a corrupção da ordem social, procurando descortinar, simultaneamente, os ideais de maioridade humana. Contudo, ao focar no conceito de ação pedagógica, Herbart deu maior concretude à relação formativa entre educador e educando, problematizando os modos específicos que tal relação assume no âmbito do governo, do ensino e da disciplina.

Herbart procura investigar a pluralidade assumida pela relação pedagógica entre educador e educando, em cada um dos três diferentes tipos de ação pedagógica, orientando-se pelo princípio pedagógico neo-humanista de que é tarefa principal da formação humana (educação geral) propiciar o desenvolvimento de todas as disposições (capacidades) humanas nas mais diferentes direções. Isto significa dizer, em outros termos, que a Pedagogia possui, como finalidade maior, a busca pelo autogoverno dos envolvidos na relação educacional, pois quem não consegue governar a si mesmo não pode fazer uso múltiplo de suas próprias disposições e, menos ainda, governar os outros. Daí a importância atribuída ao papel intelectual do educador, orientado pela formação múltipla.

Com base na interpretação de Benner formulo a hipótese de que a formação múltipla do sujeito educacional já é alcançada em parte ainda no âmbito do Governo das Crianças - primeiro capítulo do livro primeiro da referida obra -, na medida em que se deixa orientar aí pelo princípio do autogoverno pedagógico. Sendo assim, Herbart precisa, por um lado, recusar firmemente padrões (Massregeln) educacionais autoritários, como o controle rigoroso efetuado pelo adulto sobre a criança e,

1132 Educação \& Realidade, Porto Alegre, v. 43, n. 3, p. 1131-1148, jul./set. 2018. 
por outro, estabelecer a autoridade e o amor como condição da educação infantil, visando que tal educação prepare o caminho para o ensino educativo e a formação moral do caráter.

Concentrando-me no Governo das Crianças, investigo, na sequência, o tema da relação formativa entre educador e educando na perspectiva do autogoverno, desdobrando minha argumentação em dois passos argumentativos distintos, mas interligados entre si. Trato, no primeiro passo, da condição pedagógica do educando, reconstruindo a concepção herbartiana de condição infantil. No segundo passo volto-me para o perfil e o papel do educador, destacando os traços da autoridade e do amor que justificam o autogoverno pedagógico do sujeito educacional. Por fim, nas considerações conclusivas, além de resumir os resultados mais importantes dos dois momentos anteriores do ensaio, procuro, por um lado, indicar alguns limites da posição de Herbart e, por outro, assinalar a possível atualidade de seu pensamento pedagógico.

\section{A Condição Pedagógica do Educando}

Herbart não apresenta, de maneira sistemática, na Pedagogia Geral, o perfil e o papel nem do educador e nem do educando. Contudo, encontram-se, no primeiro capítulo da referida obra, indicações que permitem ao intérprete formular uma ideia geral da relação formativa entre educador e educando. Deste modo, o educando como aparece na ação pedagógica de governo é obviamente a criança, considerada desde a fase inicial, como bebê, até o final da infância, já como adolescente. O ser humano como criança possui traços específicos, mas também gerais, que pertencem a todos, independentemente de raça, cultura, religião, classe social e gênero. Decisivo é o modo como Herbart compreende a tensão entre cuidados do adulto e necessidades da criança e, sobretudo, como rejeita a forma de exercício autoritário do educador sobre o educando. Ao fazer isso, o pedagogo alemão não só se insere no espírito democrático da tradição iluminista moderna, como impulsiona as bases conceituais da pedagogia ativa subsequente.

Neste contexto, nada mais oportuno do que iniciar com a problematização acerca da condição humana infantil. Põe-se, então, a seguinte pergunta: qual é a noção de criança que sustenta a exposição do livro primeiro da Pedagogia Geral? Sua interpretação da condição infantil vincula-se estreitamente à concepção de condição humana que Herbart herda da tradição pedagógica anterior, adequando-a as suas próprias convicções educacionais. Duas noções oriundas desta tradição lhe são decisivas, perfectibilidade e educação natural. Jean-Jacques Rousseau (1712-1778) desenvolve-as exemplarmente em sua obra pedagógica Emílio (Rousseau, 1999). A referida obra contém uma teoria do desenvolvimento individualizado do educando fictício que está ancorada na disposição humana ${ }^{2}$ de aperfeiçoamento constante (noção de perfectibilidade) e na ideia de educação natural. Tal educação exige do educador que trate a criança como criança, respeitando, por um lado, a alegria própria de sua infância e, por outro, protegendo-a da invasão 
Condição Infantil e Autoridade Amorosa em Johann Friedrich Herbart

precoce dos vícios adultos ${ }^{3}$. Em síntese, a crença rousseauniana no autogoverno infantil está baseada na pluralidade das disposições humanas e na possibilidade de seu aperfeiçoamento contínuo. Esta herança torna-se decisiva para Herbart pensar a condição humana multifacetada e a própria flexibilidade infantil. Ou seja, é a noção da condição humana multifacetada e sujeita a ser perfectível que o permite perceber a flexibilidade no modo de agir da criança. É tal noção que também lhe possibilita chegar à teoria do ensino educativo (erzieherischer Unterricht), orientado pela multiplicidade do interesse (Vielseitigkeit des Interesses $)^{4}$.

Gostaria de iniciar minha interpretação com uma passagem do Governo das Crianças que sintetiza bem a ideia de educação infantil de Herbart. Com base nela passo a problematizar, na sequência, outros aspectos de seu pensamento. Assim afirma Herbart: "Onde o ambiente torna-se tão adequado de maneira que a flexibilidade infantil possa encontrar por si mesma os trilhos do que é útil e nele se complete, justamente aí o governo terá mais probabilidade de ter êxito" (Herbart, 1965, p. 35) ${ }^{5}$. Três aspectos desta passagem são importantes. Primeiro, a própria noção de flexibilidade infantil, a qual se deixa esclarecer à luz da noção de multiplicidade das disposições humanas. Justamente por ser flexível é que a condição humana se abre à possibilidade de ser modificada e de modificar-se a si mesma. Como a condição infantil é ainda mais flexível do que a condição adulta, então ela torna-se maior fonte de educação e autoeducação. Em síntese, a multiplicidade das disposições torna a criança um ser educável por excelência. No contexto da teoria educacional de Herbart, multiplicidade das disposições humanas e educabilidade constituem as duas principais dimensões da formação humana.

O segundo aspecto da passagem acima citada refere-se à noção de utilidade. Utilidade não tem a ver somente com aquilo que é proveitoso no sentido imediato. Claro, o útil refere-se a tudo aquilo que no geral faz bem à criança, tanto do ponto de vista físico e biológico, como intelectual, afetivo e cognitivo. A utilidade refere-se, por exemplo, ao cuidado com a boa alimentação da criança, a qual é indispensável a sua saúde. Do ponto de vista especificamente intelectual, que é o que mais interessa pedagogicamente a Herbart, a utilidade refere-se à finalidade da educação, ou seja, ao desenvolvimento das disposições múltiplas da criança, em direções diversas. Portanto, vinculada à finalidade, a utilidade não possui uma significação meramente pragmática, mas tem a ver com o sentido mais profundo da educação, a saber, com a formação humana múltipla, que envolve todas as disposições humanas e o seu desenvolvimento nas mais diferentes direções.

Por fim, o terceiro aspecto refere-se ao ambiente. Ele desempenha papel importante em qualquer teoria educacional e não é diferente em Herbart. O que conta, para ele, de maneira inicial, no âmbito do Governo das Crianças, é o ambiente especificamente pedagógico, o qual depende muito do perfil e do papel do educador. Cabe ao educador, deste modo, criar o ambiente suficientemente bom para o desenvolvi-

1134 Educação \& Realidade, Porto Alegre, v. 43, n. 3, p. 1131-1148, jul./set. 2018. 
mento do educando. Como o educador não pode iniciar diretamente com a atividade intelectual, é no modo como ele atende as necessidades da criança que ocorre os primeiros passos formativos. Assim, torna-se importante preparar bem o ambiente físico que está ao redor do bebê, para motivá-lo afetiva e cognitivamente. No segundo livro da Pedagogia Geral Herbart exemplifica a importância de se pendurar no carrinho do bebê figuras geométricas para que ele já possa ter as primeiras sensações do futuro objeto de seu ensino matemático.

Perceber e estimular as disposições intelectuais do educando é tarefa primordial do educador. Ele consegue fazê-lo de maneira mais adequada, como deixarei claro logo abaixo, quando, por um lado, recusar o controle rigoroso e, por outro, orientar-se pela pressão baseada na autoridade e no amor. O fato é que, para Herbart, assim como para a educação iluminista em geral, não há governo possível da criança sem o exercício pedagogicamente adequado da pressão (Druck). Deste modo, a formação humana possível ao governo das crianças precisa da pressão e não ocorre sem ela. É por meio dela que o governo se torna educativo, embora, como reconhece Herbart, há tipos específicos de pressão que são profundamente adestradores e, por isso, deformadores, como é o caso do castigo físico e do controle rigoroso.

Se a pressão assume tal centralidade no governo das crianças, é preciso perguntar pelas suas razões: por que de acordo com a crença pedagógica herbartiana o ser humano precisa de pressão? A formulação desta pergunta conduz ao núcleo da concepção herbartiana de infância. Ela se insere na pressuposição filosófico-antropológica de que é no conflito e não na harmonia que o ser humano cresce. A harmonia é algo buscado, mas que só é alcançado progressivamente, nunca de maneira definitiva, por meio de conflitos frequentes. O conflito desacomoda a criança e, ao tirá-la de sua condição inicial, a faz crescer. Mas, a pressão precisa ter uma dosagem certa e ser empregada no momento oportuno; como não há receita para isso, o próprio Governo das Crianças, por meio da pressão, se torna um enigma que precisa ser decifrado pelo educador. Ele o faz considerando o perfil das crianças, a situação momentânea e o contexto sociocultural mais amplo. Nas palavras do próprio Herbart, pesam aqui o convívio humano e a experiência de mundo tanto do educador como do educando.

A pressão, como principal exercício pedagógico do moderno governo das crianças, insere-se em uma longa tradição de pensamento, descendendo diretamente da ontologia cosmológica heracliteana do conflito dos contrários e da busca pela sua necessária unidade (Rapp, 1997). Deste modo, a pressão expressa, no âmbito pedagógico, o conflito dos contrários, caracterizando ontologicamente a assimetria pedagógica entre educador e educando. Contudo, por ser um tipo profundamente ambíguo de ação humana, a pressão carrega no seu interior, paradoxalmente, a impossibilidade do próprio crescimento. Isso acontece, sobretudo, quando é dirigida pelo controle rigoroso, o qual nega a possibilidade de autogoverno. Em todo o caso, é a ambiguidade inerente à pressão que também a faz ser tomada em sua dimensão formativa. 
Condição Infantil e Autoridade Amorosa em Johann Friedrich Herbart

Como o controle rigoroso é ineficaz para enfrentar a impetuosidade selvagem, precisa ser contraposto à pressão formativa, ancorada na autoridade e no amor. Se a pressão é necessária, como tomá-la na direção do autogoverno? O tratamento adequado desta questão exige a investigação da própria condição infantil.

Segundo Herbart, o que primeiramente aparece na criança, não é a vontade própria (Echter Wille) ${ }^{6}$, mas sim o impeto selvagem (Wilder Ungestüm), que a orienta desordenadamente para direções dispersas e contraditórias entre si (Herbart, 1965). O mundo infantil é, em seu início, um mundo caótico e desordenado, podendo transformar-se rapidamente em uma conduta viciada. Isso ocorre quando há predominância somente dos desejos destrutivos. Deste modo, a impetuosidade selvagem possui força suficiente para pôr em perigo "[...] a pessoa futura da própria criança” (Herbart, 1965, p. 31) e, por isso, precisa ser cultivada. É neste contexto que a pressão construtiva, ou seja, a pressão formativa torna-se o principal exercício de cultivo de tal impetuosidade. A tese de Herbart consiste, portanto, na ideia de que é pela pressão que a criança aprende a cultivar-se a si mesma, dominando seu ímpeto selvagem. Mas, a pressão é passageira e precisa ser superada, tão logo quanto possível, pelo ensino. Ao ser exercida pelo educador sobre o educando, a pressão deve ser firme e breve.

O parágrafo acima resume, concisamente, o núcleo da condição infantil e delineia, ao mesmo tempo, alguns traços do perfil tanto do educando como do educador. O enfrentamento do ímpeto selvagem não é obra exclusiva do educador. Se o educando não assumir seu papel e, principalmente, se o educador não estiver ciente de que o educando possui papel ativo indispensável no processo de lapidação de sua própria rudeza, a educação torna-se conservadora. Quando isso ocorre, o controle, como forma de pressão destrutiva, assume a dianteira da ação pedagógica e o ímpeto selvagem transforma-se em obediência cega, tornando a criança subserviente ao adulto e incapaz de maioridade. Mesmo sendo bem-intencionado, o educador vê seus esforços pedagógicos fracassarem porque o controle rigoroso, em vez de lapidar o ímpeto selvagem, atiça-o ainda mais, fazendo-o voltar-se contra o educador e o próprio educando.

Salta aos olhos, neste contexto, o desafio mais amplo que a $P e$ dagogia Geral assume, no âmbito do Governo das Crianças, a saber, de transformar o ímpeto selvagem em obediência ativa, a qual é condição de formação da vontade própria e, por conseguinte, da capacidade do educando de governar a si mesmo. Deste modo, a tarefa principal do governo das crianças é a preparação da passagem progressiva, conflituosa e indefinida, da impetuosidade selvagem para a vontade própria. Sem o cultivo de tal impetuosidade, não há possibilidade de autogoverno. É neste contexto que a educação possui os papéis definidos de civilização e moralização, considerando que, no contexto argumentativo do último livro da Pedagogia Geral, a formação da segurança interior é o núcleo do fortalecimento moral do caráter. De qualquer sorte, o Governo das Crianças cumpre, do ponto de vista arquitetônico da Pedagogia Geral, o

1136 Educação \& Realidade, Porto Alegre, v. 43, n. 3, p. 1131-1148, jul./set. 2018. 
papel propedêutico indispensável de preparar pedagogicamente o surgimento da vontade própria. Sem a formação da vontade própria e sem sua direção adequada não há possibilidade de autogoverno.

O que significa a impetuosidade selvagem como característica da condição infantil? Há, aqui, muitas dificuldades porque Herbart é lacônico sobre o significado desta noção. Neste aspecto, seu débito maior é com a tradição pedagógica passada, pois ele herda dela o sentido que atribui à impetuosidade selvagem. De acordo com tal tradição, e destacam-se aqui, entre os modernos, principalmente Rousseau e Kant, o ímpeto selvagem tem a ver com o estado bruto e com a rudeza que marca a criança em seu estado inicial. O estado bruto significa, por um lado, a predominância dos instintos e, por outro, a dormência das disposições intelectuais. Contudo, no caso de Rousseau, pelo fato de a condição humana ser constituída pela perfectibilidade, então ela possui internamente a força das disposições, as quais, quando são acionadas externamente pelo acaso, pela natureza ou sociedade, empurram o ser humano além dos limites impostos pela sua condição selvagem. No âmbito infantil, tornam-se decisivo, segundo Rousseau, os cuidados do adulto em relação às necessidades da criança, auxiliando-a na distinção entre necessidades reais e necessidades de fantasia. Neste contexto, a herança rousseauniana de Herbart é clara: para a noção de estado bruto ele emprega a expressão correspondente de desejos rudes; para a noção de perfectibilidade, usa a noção de multiplicidade. No âmbito da proposta mais ampla da Pedagogia Geral, governo, ensino e disciplina são formas diferenciadas de cultivo da impetuosidade selvagem, não só do educando, mas também do próprio educador.

Sendo assim, o ímpeto selvagem caracteriza justamente o tipo de ação instintiva que se deixa orientar exclusivamente pelo desejo ou inclinação e, por isso, não recebe ainda, de parte da criança, a influência da vontade. Ora, a ação orientada pelo desejo, sem a presença da vontade, torna-se desordenada. Por isso, a ação pedagógica de governo possui o objetivo de formar a ordem mínima capaz de frear a impetuosidade selvagem da criança. A crença de fundo é, para Herbart, que se os desejos não forem determinados pela vontade, a ação humana (infantil) possui grande propensão de se tornar viciada. Para evitá-lo, é preciso o exercício da pressão; contudo, para que tal exercício seja formativo, a pressão deve ser conduzida pela autoridade e pelo amor. Herbart está convicto que a conjugação destes dois tipos de pressão conduz ao autodomínio tanto do educador como do educando, tornando possível, deste modo, que o ímpeto selvagem ceda lugar, progressivamente, à obediência ativa, ou seja, à vontade própria.

Em síntese, Herbart parte da condição infantil marcada, por um lado, pelo predomínio inicial da impetuosidade selvagem e, por outro, pela ausência da vontade, a qual tornaria a criança, já em sua fase inicial, capaz de determinar minimamente seus caprichos. Ao inserir o educando no âmbito da condição humana em geral, o pedagogo alemão atribuiu-lhe a capacidade de iniciar por si mesmo um novo estado. Deste modo, por possuir a possibilidade da liberdade e por ser perfectível, 
Condição Infantil e Autoridade Amorosa em Johann Friedrich Herbart

o educando pode tornar-se sujeito ativo, capaz de fazer suas próprias experiências, e isto é fundamental para romper com a obediência cega e assegurar o princípio do autogoverno. Liberdade e perfectibilidade relacionam-se diretamente, na fase inicial do educando, com a postura do educador e com o exercício de sua autoridade educativa. Herbart deposita, neste contexto, peso decisivo ao papel intelectual pedagógico do educador, concebendo-o como responsável, por meio da pressão amorosa, pela mobilização inicial do educando, para que ele possa por si mesmo cultivar sua impetuosidade selvagem. Ocupo-me, na sequência, com o papel e o perfil do educador.

\section{A Condição do Educador}

A formação múltipla depende, no âmbito do Governo das Crianças, da pressão formativa, a qual não pode ser via de mão única, exercida somente pelo educador sobre o educando. Ela é um exercício pedagógico que implica a postura educativa adequada do adulto de tal forma que provoque a posição ativa do próprio educando. É neste contexto que se compreende porque Herbart recusa decididamente a obediência cega, pois ela refere-se à submissão irrestrita do educando ao educador, levando-o a se curvar silenciosamente à pressão autoritária adulta. Obediência cega é sinônimo de servidão e, portanto, ausência de liberdade, bloqueando também a perfectibilidade humana. $O$ fato é que a servidão impede o autogoverno em todas as suas dimensões, pedagógica, moral e política. Ora, somente quando a pressão for formativa é que ela deixa de ser autoritária, pois abre espaço para a ação do próprio educando, permitindo-lhe elaborar intelectualmente suas próprias experiências. Como se apresenta, neste contexto, a postura do educador?

Esta é uma pergunta educacional chave à tipologia tripartite da ação pedagógica e, por conseguinte, especificamente da ação pedagógica de governo. $\mathrm{O}$ autogoverno pedagógico depende muito, no âmbito do Governo das Crianças, da postura do educador. Neste sentido, ele (o educador) não pode esquecer que sua meta maior é, no âmbito da educação familiar, o cultivo da alma das crianças, e os exercícios que ele propõe ou recusa devem ter isso em conta. Ou seja, os exercícios pedagógicos que o educador pretende desenvolver junto às crianças devem visar à formação intelectual, com o intuito de torná-las seres com vontade própria. Neste sentido, a formação da vontade própria da criança é condição para seu autogoverno. Tendo este pano de fundo em mente, Herbart procura distanciar-se criticamente de alguns exercícios padrões que os educadores da época empregavam com seus educandos. Além de se distanciar do castigo físico e da educação livresca, baseada no manuseio autoritário do manual didático, ele também se afasta, quando trata diretamente dos padrões do governo das crianças, do controle rigoroso e constante, exercido pelo educador sobre o educando.

É importante atentar, primeiramente, para a noção de padrão (Massregel), com o intuito de compreender a recusa decidida do controle como técnica autoritária de governo. Embora Herbert não o defina

1138 Educação \& Realidade, Porto Alegre, v. 43, n. 3, p. 1131-1148, jul./set. 2018. 
precisamente, fica subentendido, no texto, que a noção de padrão diz respeito às referências que definem e orientam, do lado do educador, sua postura na relação que mantém como o educando. O padrão pode ser tanto positivo como negativo, ou seja, do ponto de vista pedagógico, pode tanto formar como deformar. Sendo assim, quando se reporta ao controle, Herbart está indicando negativamente o modo de governo que o adulto não deve assumir em relação à criança e a si mesmo, pois querendo controlar rigorosamente a criança, torna-a obediente passivamente. Como a meta é formação múltipla de todas as disposições humanas em todas as direções, visando o autogoverno do sujeito educacional, então o padrão educacional precisa ser ele próprio educativo.

O que está em jogo aqui é a recusa do espírito manipulador, que quer ter tudo sob seu controle e, para tê-lo, precisa obviamente subjugar quem está ao seu redor. Por isso, a pressão precisa ser formativa, pois do contrário dá origem ao espírito manipulador. De qualquer modo, criticando o controle como forma destrutiva de governo, Herbart diz então, primeiro, o que o governo não deve ser, para oferecer depois indicações de como ele poderia ser. Um governo que vise o autogoverno não pode se basear no controle rigoroso e vigilante, simplesmente porque tal forma de pressão adestra e não educa a criança. Além de adestrar, cria na criança o espírito manipulador, tornando-a, por um lado, submissa à autoridade superior e, por outro, opressora sobre quem está sob seu domínio. Deste modo, governar pela pressão, mas sem adestrar, é a finalidade maior do governo das crianças; mas, tal finalidade põe muitas exigências pedagógicas ao sujeito educador, difíceis de serem cumpridas.

Herbart destaca, em uma passagem do livro primeiro da Pedagogia Geral, o efeito destrutivo que o controle rigoroso exerce no governo das crianças. Assim afirma ele: "Além disso, [o controle] impede as crianças de se tornarem elas próprias, de se experimentarem a si mesmas e de conhecerem mil coisas que jamais são empregadas no sistema pedagógico, mas que só podem ser procuradas por meio da busca individual" (Herbart, 1965, p. 32). O controle rigoroso tira a autonomia própria à fase infantil, impedindo a criança de se iniciar na arte de pensar por conta própria. Além de não deixar a criança ter vida própria, leva à dissimulação como forma inautêntica de reagir ao controle rigoroso. A criança, sentindo-se permanentemente vigiada e buscando escapar do olhar clínico rigoroso do adulto, cria subterfúgios, os quais nem sempre a conduzem a adotar comportamentos apropriados.

Isso significa dizer que o controle rigoroso provoca, na convivência prática, o efeito contrário ao almejado: em vez de educar a criança, termina por corromper seu espírito; em vez de formá-la para a autonomia, torna-a dependente do comportamento viciado. Se não bastasse isso, Herbart deixa claro, na parte final da passagem acima citada, que o controle mata a curiosidade da criança, impedindo-a de fazer suas próprias buscas. Em síntese, o exercício do controle e da vigilância impede que o educando seja ele mesmo. Ora, e esta talvez seja a principal consequência perniciosa da educação autoritária, o aniquilamento da formação de si mesmo bloqueia por completo a possibilidade do auto- 
Condição Infantil e Autoridade Amorosa em Johann Friedrich Herbart

governo. A consequência política desastrosa é evidente: sem a formação do si mesmo não há autogoverno e, sem ele, qualquer possibilidade das formas democráticas de vida. Sendo assim, deixando-se orientar pelo controle rigoroso (educação autoritária), o Governo das Crianças não desempenha o papel propedêutico de preparar o sujeito educacional para o ensino e à disciplina.

Contudo, há ainda outro aspecto, da passagem acima, que permite compreender o papel do educador em relação à finalidade mais ampla da Pedagogia Geral. Ele precisa recusar, visando à formação da vontade própria dos envolvidos no processo pedagógico, não só o controle como forma de governo, mas também o sistema pedagógico. Por sistema pedagógico entende Herbart a doutrina educacional deduzida do sistema filosófico ou científico. Sua recusa ao sistema está subentendida na diferença que estabelece entre sistema pedagógico e busca individual. Tal recusa ocorre em nome da individualidade dos envolvidos no processo pedagógico. A noção de busca individual é decisiva porque exige a postura de reconhecimento que o educador precisa ter em relação ao educando. Trata-se da forma de reconhecimento que vai muito além do interesse sistemático da Pedagogia e do controle rigoroso como técnica pedagógica. Somente quando liberto desta dupla amarra, do interesse pelo sistema e do controle rigoroso, é que o educador pode enxergar o educando como ele é, ou seja, como sujeito educacional que faz suas próprias descobertas. Em síntese, é do distanciamento em relação ao sistema que conduz o educador a tomar o educando na multiplicidade de suas disposições, contribuindo para orientá-las nas direções diversas. Deste modo, educação para o autogoverno implica o respeito pela individualidade do sujeito educacional.

Livre de tais amarras, o educador pode considerar o educando em seu próprio mundo, como um ser agente capaz de exercitar a si mesmo. Ora, o controle permite exatamente o contrário: “Ao impor-se, porém, o controle como regra, não se exija agilidade, espírito inventivo, ousadia ou comportamento confiante daqueles que cresceram sob tal pressão" (Herbart, 1965, p. 33). Em síntese, a pressão do controle rigoroso mata a liberdade e a criatividade da criança. Este posicionamento duro de Herbart contra o controle mostra o quanto ele estava consciente de seu efeito destrutivo na formação do educando. Como técnica de pressão, o controle não se torna educativo porque adestra o educando: em vez de formá-lo, deforma-o.

O repúdio ao controle rigoroso como forma de pressão não significa, porém, a negação completa da pressão como exercício pedagógico. Herdeiro da tradição iluminista, Herbart está convencido de que a formação moral da vontade precisa do exercício de regras, o qual, por sua vez, depende da pressão. Mas, que tipo de pressão é então legítima? Surge aqui, à primeira vista, uma contradição quase insolúvel, porque a pressão parece negar a ação educativa. Daí emerge o conhecido dilema pedagógico clássico: como conciliar a liberdade, que é a condição da autonomia da vontade, com a pressão? Herbart insere-se, neste ponto, nitidamente, nos trilhos do problema formulado por Kant, décadas an-

1140 Educação \& Realidade, Porto Alegre, v. 43, n. 3, p. 1131-1148, jul./set. 2018. 
teriores, em suas preleções Sobre Pedagogia (Über Pädagogik): "Pois, a pressão é necessária! Como eu cultivo a liberdade mediante a pressão?” (Kant, 1998, p. 711).

Depois de ter criticado o controle rigoroso como deformação da condição infantil, Herbart volta-se para duas formas legítimas de pressão pedagógica, a autoridade e o amor. Ele parte do pressuposto de que o exercício da autoridade adulta é indispensável para desencadear o autogoverno infantil. A autoridade não deve ser confundida com o autoritarismo, uma vez que este, como ficou claro acima, é próprio do controle vigilante. Mas, de onde brota a autoridade legítima? Ela brota, segundo o autor, da superioridade de espírito: "Porém, a autoridade só se adquire por meio da superioridade do espírito” (Kant, 1998, p. 33). Contudo, considerando a rudeza e a impetuosidade inicial da criança, a superioridade do espírito, que nada mais é do que o autodomínio de si mesmo, precisa ser formada e, neste processo de formação, a presença da autoridade adulta é decisiva. Suas palavras, suas afeições e, sobretudo, seu modo de proceder calam fundo no caráter em formação da criança. Sendo assim, é claro que a superioridade do espírito emana primeiramente do educador, sendo de sua responsabilidade exercê-la de tal modo que propicie o governo de si mesmo do educando.

A superioridade de espírito possui, segundo Herbart, um núcleo intelectual, desdobrado em uma dupla dimensão, interligada entre si. A primeira dimensão é nitidamente ético-pedagógica, relacionando-se com a postura exemplar do educador. Para que possa influenciar formativamente no desenvolvimento da condição infantil, o educador (pai ou professor) precisa tornar-se ele próprio um bom exemplo para a criança. Neste contexto, a ação exemplar repousa na coerência constante entre o que o educador diz e o que ele faz; seu compromisso em dizer a verdade deve corresponder ao seu modo de ação. Tal coerência ética obriga seu respeito pelo convívio humano e experiência de mundo do próprio educando. De outra parte, a supremacia de espírito do educador advém de seu domínio de conhecimento. Para que possa ser referência na formação do educando, o educador (como preceptor) precisa possuir domínio intelectual amplo, conhecendo em profundidade os temas a serem tratados. A formação intelectual múltipla do educador é indispensável para que possa contribuir com o desenvolvimento das diversas disposições do educando.

Portanto, a superioridade de espírito do educador possui dimensão nitidamente intelectual, de cunho ético-pedagógico e cognitivo. Cabe destacar, contudo, que o núcleo pedagógico fundador de sua superioridade de espírito repousa, em última instância, no respeito pela condição ativa do educando, tomando-o desde o início como capaz de tornar-se sujeito de suas próprias ações. Do lado do educando, por sua vez, a dimensão ética e pedagógica vem expressada no respeito e na admiração pelo seu educador, vendo nele o exemplo a ser seguido. Mas, como se trata do respeito que brota da coerência moral que vê no mestre educador, o educando assume uma obediência que não é passiva ou cega em relação à autoridade do educador. Ou seja, movido pelo 
Condição Infantil e Autoridade Amorosa em Johann Friedrich Herbart

exemplo do mestre, ele vê-se obrigado a tomar a si mesmo como sujeito ativo, que deve responsabilizar-se por suas próprias ações. Embora esta perspectiva ideal de relação entre mestre e discípulo valha mais para as ações pedagógicas do ensino e da disciplina, deve esboçar-se já no âmbito do Governo das Crianças.

De qualquer forma, a autoridade é algo a ser conquistado e não concedida ou tomada de empréstimo. Como laço pedagógico vinculante entre educador e educando, a autoridade não pode ser dada, mas sim formada. Isso vale para ambos, tanto ao educador como ao educando. O educador conquista o respeito de sua própria autoridade quando não a exerce com base no controle rigoroso, pois exercendo desta maneira, transforma-se em educador autoritário, negando a si mesmo, como ser humano. Nesta condição, o educando na verdade não o respeita, mas o teme, sendo, neste caso, o temor e não o amor o sentimento que o vincula ao seu educador. De outra parte, é o procedimento contrário ao autoritarismo que permite o educador respeitar a condição do educando. Tem consciência que sua condição se iguala à condição de seu educando num aspecto decisivo, a saber, ambos possuem a possibilidade (ontológica) da obediência ativa, ou seja, de serem sujeitos ativos capazes de fazerem suas próprias buscas e descobertas. Deste modo, o educando, ao perceber a dimensão formativa da autoridade do educador, respeita-a, tomando-a como exemplo para si mesmo. Espelha-se no autogoverno amoroso do educador para construir seu próprio autogoverno. O educando, sendo reconhecido em sua liberdade e iniciativa, sente-se posteriormente interessado no desenvolvimento progressivo e múltiplo de seus estados de espírito (Gemütszustäden).

O amor é, juntamente com a autoridade, outra forma legítima de pressão. É a força propulsora de legitimação da possibilidade do exercício não autoritário da autoridade. Herbart não dedica muito tempo para falar do amor. Embora telegráfico neste assunto, inspira-se em uma longa tradição pedagógica que, iniciando com o Eros platônico, passa pelo Agapé cristão e desemboca no amor pedagógico de Johann Heinrich Pestalozzi (1746-1827), sua fonte de influência maior e mais próxima. Pestalozzi considera o amor pedagógico como força motriz principal do processo auto formativo do sujeito educacional, caracterizando, com isso, especialmente a relação formativa do educador com o educando. A figura da mãe Gertrud representa, no âmbito do romance educacional Lienhard e Gertrud, a educadora ideal que forma a criança para o modo de agir flexível, depositando grande valor na autoatividade, ordem e responsabilidade moral da criança. A própria ideia de autogoverno, baseada na autoatividade livre do educando, ocupa lugar central neste romance de Pestalozzi (Uhle; Gaus, 2002). Em síntese, ao colocar o sentimento do amor como núcleo do desenvolvimento inicial da criança, Pestalozzi o concebe também como disposição mediadora da relação pedagógica entre o adulto e a criança, atribuindo-lhe o papel de fonte originária do desenvolvimento das demais disposições do educando.

Herbart compreende, no Governo das Crianças, que autoridade e amor se implicam mutuamente, pois um sem o outro enfraquece a 
pressão como exercício formativo do educando. Mas, de que amor se trata? O amor, baseando-se na harmonia de sentimentos, estabelece o laço afetivo que une familiarmente as pessoas entre si. Como o Governo das Crianças refere-se prioritariamente à educação familiar (doméstica), o amor é o laço afetivo que une pais e filhos, especialmente mãe e criança. Ele torna-se, deste modo, o laço afetivo indispensável que dá unidade à família, tornando perceptível, inclusive, a importância da própria autoridade nas relações educativas.

Portanto, para que ocorra o processo formativo, os laços entre educador e educando precisam estar apertados, próximos, e o amor representa este laço afetivo que prende entre si os dois polos da ação pedagógica, o educador e o educando. No âmbito da relação entre adulto e criança, que é o âmbito do governo como ação pedagógica, cabe ao educador tomar a iniciativa de abrir-se ao afeto e simpatia da criança. Precisa cultivá-la para poder exercer a pressão pedagógica almejada. Sem a criação do laço afetivo não há como chegar à formação da vontade. Isso é indispensável ao próprio educando, como alerta Herbart (1965, p. 34), pois este "[...] só pode dar força às relações criadas, se lhe for possível interagir de qualquer modo com o educador”. Um educador fechado, sisudo, sem afeição ao seu educando, não só tranca-lhe a porta de acesso ao saber, como também bloqueia o desenvolvimento afetivo de seu educando.

Neste contexto, fica claro que sem a presença do amor, a autoridade do educador corre risco de se tornar autoritária, degenerando-se em deformação. A autoridade sem amor não pode cumprir seu papel formativo porque lhe falta o afeto vinculante que faz a superioridade de espírito do educador tornar-se pedagogicamente interessante ao educando. Na ausência do amor, o educando teme o educador, mas não o respeita. Sem o sentimento do amor, o adulto exerce friamente sua autoridade, fazendo valer irrestritamente sua superioridade sobre a condição flexível do educando. Deste modo, quando falta o amor, a autoridade pode tornar-se facilmente fria e calculista, contribuindo para que o próprio educando torne-se autoritário e manipulador.

Em síntese, do argumento de Herbart sobre o amor é possível extrair um duplo papel pedagógico: por um lado, o amor impulsiona e intensifica a orientação intelectual que o educador precisa exercer na formação do educando; por outro, auxilia na compreensão das necessidades da criança. $\mathrm{O}$ amor é, então, o sentimento de afeto que permeia a tensão entre as necessidades da criança e os cuidados do adulto e, conforme salienta Herbart, acentua o esforço dos pais para encontrar o tom na compreensão dos sentimentos e necessidades de seus filhos. Deste modo, é pelo amor que o adulto encontra a maneira construtiva de se relacionar com a criança, descobrindo-a naquilo que ela é, ao mesmo tempo em que possibilita ao educador descobrir-se a si mesmo, como educador. 
Condição Infantil e Autoridade Amorosa em Johann Friedrich Herbart

\section{Considerações Finais}

Johann Friedrich Herbart desenvolve, em sua Pedagogia Geral, um modelo próprio de autogoverno pedagógico, o qual pressupõe, no âmbito do Governo das Crianças, uma postura formativa específica tanto do educador como do educando. Tal postura baseia-se na ideia da condição humana constituída por disposições diversas, sujeitas a se aperfeiçoarem constantemente. Ele coloca no centro de sua teoria educacional infantil a noção de pressão formativa, distinguindo os diferentes padrões que ela assume no contexto da relação educativa. Quando toma a forma do controle rigoroso e vigilante, a pressão torna-se autoritária porque bloqueia a possibilidade de autogoverno do educando. A criança, quando está sob o controle do adulto, sendo permanentemente vigiada por ele, não pode fazer de maneira criativa suas próprias experiências. Tendo que se esconder permanentemente da opressão adulta, não possui a liberdade necessária para desenvolver suas disposições nas mais diferentes direções. Ela é privada, deste modo, de algo indispensável ao processo formativo humano, a saber, da descoberta do mundo e, simultaneamente, da autodescoberta de si mesma. De outra parte, a pressão torna-se realmente formativa, assumindo o papel pedagógico indispensável de proporcionar a independização progressiva da criança, quando o adulto consegue exercer sua autoridade de maneira amorosa. Segundo Herbart, pai e mãe não podem renunciar, no âmbito familiar, respectivamente, da autoridade e do amor.

Este resumo dos resultados obtidos com a investigação empreendida acima permite-me balizar agora, brevemente, alguns limites inerentes à educação infantil de Herbart, atendo-me, especificamente, por um lado, na sua concepção patriarcal de família e, por outro, na distinção dicotômica entre educação privada e educação pública. Com tal resumo gostaria de indicar, também, na sequência, uma possível atualidade de seu pensamento pedagógico referente à educação infantil.

A Pedagogia Geral é tributária do espírito de seu tempo, incorporando, em certo sentido, a cultura patriarcal dominante. Neste contexto, a ideia de educação infantil que subjaz ao Governo das Crianças assume papeis bem distintos destinados ao pai e à mãe no âmbito da estrutura familiar. A autoridade atribuída ao pai e o amor à mãe são conquistados mediante a distinção hierarquizada destes dois padrões educacionais. Ao naturalizar tal distinção, Herbart certamente deixa de potencializar as disposições de autoridade e de amor na formação múltipla do sujeito educacional, especialmente, do educando. Não consegue visualizar a autoridade amorosa como forma recíproca de procedimento de ambos, pai e mãe, no seu relacionamento com seus filhos.

Tributário de seu tempo, o Governo das Crianças também se insere na concepção educacional estandarte da época, distinguindo rigidamente entre educação privada e educação pública. Limita a educação privada ao âmbito familiar, atribuindo-lhe duplo papel: por um lado, guiando-se pelo sentimento de amor, a família deveria ser a incubadora dos laços afetivos primários indispensáveis à ampla socialização futu- 
ra da criança; também deveria ser, por outro, o espaço garantidor da sobrevivência física e biológica do educando, precisando proteger, por meio da educação natural negativa, a criança da sociedade adulta corrompida. De outra parte, Herbart insere a educação pública no âmbito escolar e social mais amplo, atribuindo-lhe o papel de refletir sobre os direitos e deveres gerais que vão muito além do âmbito familiar. $\mathrm{O}$ fato é que ao estabelecer tal distinção, Herbart vê-se impedido de investigar mais a fundo a complexidade que constitui cada uma destas esferas educacionais e de perceber, adequadamente, o quanto é indispensável, para a existência individual de cada uma delas, a família e a escola, a própria imbricação entre elas. Ou seja, em última instância, o espaço público democrático ocupado pelos adultos depende em grande medida da qualidade da educação infantil. A saúde da sociedade adulta depende da boa educação das crianças, pois é no âmbito de tal educação que começa a se desenvolver a individualidade do ser humano.

Em síntese, a forte dicotomia entre educação doméstica e educação pública impediu Herbart de visualizar, com maior clareza, os efeitos positivos da educação natural (doméstica) para a constituição política e moral da educação pública. O educando que aprende desde a infância os exercícios práticos, como a higienização do corpo e o horário regular para fazer suas refeições e ir para a cama, cultiva uma forma de vida que não só o torna resistente aos vícios, como também o capacita para assumir, progressivamente, regras sociais e morais mais amplas. Portanto, os laços afetivos iniciais, baseados no ambiente familiar suficientemente acolhedor, possuem, como mostrou mais tarde Donald Winnicott (2002) uma influência duradoura na vida do ser humano, orientando o posicionamento ético e político da vida adulta em sociedade.

No que se refere à possível atualidade da educação infantil de Herbart, é visível o quanto as noções de autoridade e amor impulsionaram o desenvolvimento das pesquisas posteriores ${ }^{7}$. Contudo, o teor altamente esclarecedor que a questão de gênero assumiu nos séculos posteriores a Herbart, permite superar o sentido patriarcal que orienta os padrões de autoridade e amor limitados, respectivamente, às figuras paterna e materna ${ }^{8}$. Se, por um lado, tal distinção rigorosa de gênero não faz o menor sentido na atualidade e, por outro, não podemos mais renunciar às noções de autoridade e amor como categorias fundantes da ação pedagógica, por causa da influência tanto das próprias ideias de Herbart como das pesquisas educacionais posteriores, estamos hoje em melhores condições de pensar na pedagogia da autoridade amorosa. Tal pedagogia pode assumir a tarefa primordial de atribuir equitativamente papeis educacionais para os adultos de referência mais próxima da criança, independentemente da distinção de gênero entre homem e mulher, pai e mãe. Deste modo, a autoridade amorosa seria resultado do exercício recíproco e simultâneo de papeis assumidos simultaneamente pelos adultos em relação às crianças. Pai e mãe podem assumir ao mesmo tempo tanto a autoridade como o amor, fazendo da autoridade amorosa o pilar da socialização afetiva e formativa da criança. 
Condição Infantil e Autoridade Amorosa em Johann Friedrich Herbart

De outra parte, as pesquisas de Niklas Luhmann e Axel Honneth auxiliam para esclarecer, na atualidade, o sentido antropológico, social e ético que a noção de amor assume no amplo processo de formação humana. O amor é, para Luhmann (1999), um código de comunicação semântica que expressa relações interpessoais íntimas. Deste modo, são atribuídas ao amor funções sociais normativas que o tornam o elo vinculante entre os participantes de uma determinada comunidade social que se orientam interagindo comunicativamente. Como parte da gramática social marcada pelo espírito de época, o amor permanece aberto à preferência semântica de cada comunidade, ganhando sentido e significado no âmbito de padrões socioculturais determinados. Portanto, com esta posição teórica Luhmann contribui para que a noção de amor ultrapasse a significação meramente romântica e seja compreendido na perspectiva de sua sociabilidade histórica.

Por fim, Axel Honneth (1994), partindo do pensamento do jovem Hegel, insere o amor na ampla teria do reconhecimento, considerando-o como uma das principais forças propulsoras do reconhecimento recíproco. Baseando-se em estudos da tradição neofreudiana, Honneth ressalta a importância do amor que brota da relação dos adultos de referência mais próxima com a criança, visando a socialização saudável do futuro adulto. A criança que encontra um ambiente afetivo acolhedor já na primeira infância, estará certamente melhor preparada psíquica e intelectualmente para enfrentar as dificuldades e desafios da sociedade adulta.

Para concluir, a crítica à concepção de educação infantil de Herbart e sua necessária ampliação ressalta ainda mais a importância de suas ideias pedagógicas. A relação do adulto com a criança que promove o desenvolvimento múltiplo das disposições humanas não pode recusar a autoridade e o amor como padrões culturais e intelectuais vinculantes da relação pedagógica. $\mathrm{O}$ autogoverno pedagógico, com seus desdobramentos éticos e políticos, necessita hoje, talvez ainda mais do que a época de Herbart, da autoridade amorosa.

Recebido em 10 de julho de 2017 Aprovado em 15 de janeiro de 2018

\section{Notas}

1 Agradeço ao CNPq pela Bolsa Produtividade em Pesquisa, a qual tornou possível o desenvolvimento da presente investigação.

2 A noção de disposição humana é central às teorias educacionais modernas, indicando seu entrelaçamento com a antropologia de matriz filosófica. O ser humano é constituido por múltiplas disposições, sendo a principal delas a capacidade de se aperfeiçoar indefinidamente, para todas as direções; portanto, sem um fim único previamente determinado.

3 Para a noção de perfectibilidade ver Dietrich Benner e Friedhelm Brüggen (1996) e Claudio Almir Dalbosco (2016); para a educação natural ver Alfred Schäfer (2002) e Claudio Almir Dalbosco (2011).

1146 Educação \& Realidade, Porto Alegre, v. 43, n. 3, p. 1131-1148, jul./set. 2018. 
4 Estes dois conceitos constituem o núcleo central do segundo livro da Pedagogia Geral e não serão abordados aqui.

5 As traduções do texto de Herbart são de minha própria autoria, bem como de toda a literatura alemã empregada.

6 A noção de vontade forma, segundo Herbart, o núcleo da formação moral do ser humano. Deixando-se orientar pela virtude, a vontade torna-se capaz de se autodeterminar frente às seduções constantes que os vícios representam à ação humana. Como a criança não nasce com a vontade pronta, ela torna-se um problema pedagógico de primeira grandeza, porque precisa ser formada. O problema da formação virtuosa da vontade é central à tradição pedagógica iluminista, principalmente para Rousseau e Kant. Herbart insere-se nitidamente nesta tradição.

7 Para estudos especializados sobre a condição infantil ver, entre outros: Jessica Benjamin (1990); William Damon (1990) e Martin Dornes (2003).

8 Para este tema, diante da vastidão literaria existente, ver especialmente Martha Nussbaum (2002)

\section{Referências}

BENJAMIN, Jessica. Die Fesseln der Liebe: psychoanalise, Femenismus und das Problem der Macht. Basel; Frankfurt: Suhrkamp, 1990.

BENNER, Dietrich. Die Pädagogik Herbarts: eine problemgeschichtliche Einführung in die Systematik neuzeitlicher Pädagogik. Weinheim; München, 1993. BENNER, Dietrich; BRÜGGEN, Friedhelm. Das Konzept der Perfectibilité bei Jean-Jacques Rousseau: ein versuch, rousseaus programm theoretischer und praktischer urteilsbildung problemgeschichtlich und systematisch zu lesen. In: HANSMANN, Otto (Hrsg.). Seminar: der pädagogische Rousseau: band II: kommentare, interpretationen, wirkungsgeschichte. Weinheim: Deutscher Studien Verlag, 1996. P. 12-48.

DALBOSCO, Claudio Almir. Educação Natural em Rousseau: das necessidades das crianças e dos cuidados dos adultos. São Paulo: Cortez Editora, 2011.

DALBOSCO, Claudio Almir. Condição Humana e Educação do Amor Próprio em Jean-Jacques Rousseau. São Paulo: Edições Loyola, 2016.

DAMON, Willian. Die Soziale Welt des Kindes. Frankfurt: Suhkamp, 1990.

DORNES, Martin. Die Frühe Kindheit: entwicklungspsychologie der ersten lebensjahre. Frankfurt; Main: Fischer, 2003.

HERBART, Johann Friedrich. Pädagogische Schriften: zweiter band: allgemeine pädagogik, aus dem zweck der erziehung abgeleitet. Düsseldorf; München: Verlag Helmut Küpper Vormals Georg Bondi, 1965.

HONNETH, Axel. Kampf um Anerkennung: zur moralischen grammatik sozialer konflikte. Frankfurt am Main: Suhrkamp, 1994.

KANT, Immanuel. Schriften zur Anthropologie, Geschichte, Politik und Pädagogik, Band VI. In: KANT, Immanuel. Werke in Sechs Bänden: Herausgegen von Wilhelm Weischedel. Darmstadt: WBG, 1998.

LUHMANN, Niklas. Liebe als Passion: zur codierung von intimität. Frankfurt: Suhrkamp, 1999.

NUSSBAUM, Martha. Las Mujeres y el Desarrollo Humano. Barcelona: Herder, 2002.

Educação \& Realidade, Porto Alegre, v. 43, n. 3, p. 1131-1148, jul./set. 2018. 
RAPP, Christof. Vorsokratiker. München: Becker, 1997.

ROUSSEAU, Jean-Jacques. Oeuvres Complètes: tomo IV: Emile. Paris: Gallimard, Bibliothèque de la Plêiade, 1999.

SCHÄFER, Alfred. Jean-Jacques Rousseau: ein pädagogisches porträt. Weinheim; Basel: Beltz Verlag, 2002.

UHLE, Reinhard; GAUS, Detlef. Pädagogischer Eros: hoffnung auf intimität oder professionelles ethos? ein problem aufriss. In: FAULSTICH, Werner; GLASENAPP, Jörn (Hrsg.). Liebe als Kulturmedium. München: Piper, 2002. P. 81-120. WINNICOTT, Donald. Vom Spiel zur Kreativität. Stuttgart: Klett-Cotta, 2002.

Cláudio Almir Dalbosco é professor de Filosofia da Educação dos Cursos de Filosofia e Pedagogia e do PPGEDU da Universidade de Passo Fundo (UPF/RS). E-mail:vcdalbosco@hotmail.com

Este é um artigo de acesso aberto distribuído sob os termos de uma Licença Creative Commons Atribuição 4.0 Internacional. Disponível em: $<$ http://creativecommons.org/licenses/by/4.0>. 